\title{
Analytical report on post traumatic hydrocephalus
}

\author{
R. Srinivas, Mohamed Naleer \& Kishore Kumar
}

Department of Neurosurgery, Sri Ramachandra Institute of Medical Sciences and Research, Chennai, Tamilnadu, India.

\section{CORRESPONDING AUTHOR}

Dr. R. Srinivas, Department of Neurosurgery, Sri Ramachandra Institute of Medical Sciences and Research, Chennai, Tamilnadu, India.

Email: drsrinivas74@gmail.com

\section{ABSTRACT \\ BACKGROUND}

Post-traumatic hydrocephalus (PTH) is a field and disorder less explored in neurosurgery though we see many cases. The commonest causes in our set up includes head injury for which people have undergone decompressive craniectomies, severe head injuries with raised ICP. We did a clinical analysis on 23 cases in a period of 3 years duration from $2018-2021$. We did Evd in few cases for emergency purposes when there was decerebration and we went ahead with VP shunt in all the patients who had gross ventricular dilatation. We have projected our analytical report in these cases.

\section{METHODS}

A retrospective study was conducted in the Department of Neurosurgery in Sri Ramachandra medical college. The clinical outcome of patients diagnosed with PTH was studied. These cases were treated by surgery. The stastical analysis along with cause of the hydrocephalus with the outcome in pre and postoperative period were studied.

\section{RESULTS}

Among the 23 patients studied $82 \%$ were males. Road traffic accident was the main cause of injury. The other main cause was a fall from height. Assault was another reason for head injuries which we recorded. We found all road traffic accidents were only because of bike riders either pillion or the people driving the vehicle. . Craniotomy was done in $50 \%$ of the patients, $90 \%$ of the patients recovered who had a gcs of 13 to 7 . People with gcs lss than 7 were intubated recovery rate was $7.5 \%$. There was $100 \%$ mortality because of primary head injury in all the patients who had brain stem contusions with dilated pupil.

\section{CONCLUSIONS}

Trauma to head and who were operated had the highest incidence of post tramatic head injury. Smaller the decompressive craniectomies had symptomatic post traumatic head ache with post traumatic hydrocephalus.. CT scan of the brain is considered the choice of investigation to 
early diagnose PTH.we even analysed the ct scan and found when there was periventricular lucency the patient outcome after VP shunting is good.

\section{KEY WORDS}

Hydrocephalus, Head Injury, Trauma

\section{BACKGROUND}

The common age group was 40 who had sustained road traffic accidents. The patients who had intracranial hematomas had undergone surgery .only patients people who had smaller craniectomies developed earlier PTH after surgery. The patients who had severe head injury like diffuse axonal injury developed hydrocephalus long time after the initial injury. They were even symptomatic like headache and seizures. Some people were dormant and asymptomatic and mute because of frontal lobe damage. People who had severe hydrocephalus had symptoms like urinary disturbances along with papilledema. Patients with diffuse axonal injury developed the signs at a later duration after primary head injury. In patients with low gcs whom we had a doubt whether improvement will occur we did a lumbar puncture. When we found opening pressure was between $18-25 \mathrm{~cm}$ of csf we went ahead with V.P.shunt.

\section{METHODS}

This was a prospective study done in year 2018-2021, this study was done on 23 patients of PTH managed in a tertiary care hospital between 2018-2021.. All patients satisfying the selection criteria during the study period were included. We analysed things like mode of injury , duration after which they developed PTH.The prognostic criterias the outcome of surgical procedurewere analysed. Clinical features were reported and radiological criteria of the presence of ventriculomegaly with periventricular lucencies in non-contrast CT scan was considered as standard criteria for surgical intervention. This was done to eliminate ventriculomegaly caused due to loss of brain tissue (hydrocephalus ex-vacuo). Patients were treated with medium pressure ventriculoperitoneal shunts. Postoperative outcomes and complications were recorded.

\section{Statistical Analysis}

Head injury and type of injury were considered as primary cause, mode of injury varied. Postoperative GCS and patient outcomes were considered as outcome variables. Descriptive statistics was done by frequency and percentage for all study variables.

\section{RESULTS}

Data from 23 patients were analyzed. A majority $82 \%$ were males and $40 \%$ belonged to the 40 to 60 years age group .For post-traumatic hydrocephalus, Road traffic accidents (RTA) $(55.5 \%)$ and fall $(34 \%)$ were the most common mode of trauma. The majority $(50 \%)$ had traumatic subarachnoid haemorrhage (SAH) on CT scans. Preoperative GCS ranged from 9 to 12 in a majority of the patients (66.67 \%)before V.P. shunt. Postoperative GCS ranged between 13 and 14 in $72.23 \%$ of the patients. Opening pressure on lumbar puncture was $13-15 \mathrm{~cm}$ of $\mathrm{H} 2 \mathrm{O}$ in 
$55.5 \%$ of the patients. All $100 \%$ of the patients had CT features of hydrocephalus who were taken into our analysis. Among 23 patients, multiple symptoms were present such as headache, drowsiness, visual disturbance etc. ... Among the 23 patients, 18 recovered completely.

\section{DISCUSSION}

In the present study, a total of 23 cases with head injury developed post-traumatic hydrocephalus. In our study we considered only patients with ventriculomegaly for evaluation and followup. This study's results showed that post-traumatic hydrocephalus presents with different symptoms like altered sensorium, drowsiness, headache, vomiting and seizures. Cardoso et al. suggested that post-traumatic hydrocephalus can present with varied clinical features such as altered sensorium, failure to improve, psychomotor hindrance, loss of memory, ataxic gait, urinary and anal incontinence. Coma for a long duration or sudden deterioration in conscious patients should caution the development of hydrocephalus. . Contusion was the most common finding in our study. Traumatic SAH was the second most common pathology in our study. In some studies subarachnoid haemorrhage (SAH) has been mentioned as the most common cause that leads to the development of PTH. ${ }^{7,20-22}$

Hydrocephalus can occur in posttraumatic conditions. Based on this study's result, PTH was seen in young patients (younger than 40 years of age). This shows that it is need of the hour to use preventive programs to reduce the occurrence of trauma in this young productive age group. Since PTH is also observed in mild head injury, early diagnosis and timely treatment are warranted, thereby reducing hospital costs and long-term hospitalization. Future studies on long term follow up and large analytical studies are recommended.

\section{CONCLUSIONS}

Post-traumatic hydrocephalus is a consequence of traumatic brain injury and can present with various neurological features after variable days of the initial trauma. CT scan is considered as the investigation of choice for early diagnosis of PTH and to rule out other possibilities of delayed deterioration in a recovering head injury patient. PTH has a very good outcome after VP shunting.

\section{REFERENCES}

1. Majdan M, Plancikova D, Brazinova A, et al. Epidemiology of traumatic brain injuries in Europe: a cross-sectional analysis. Lancet Public Health 2016;1(2):e76-e83.

\section{CrossRefl Google Scholar| $\mid \underline{\text { PubMed }}$}

2. Marmarou A, Foda MA, Bandoh K, et al. Posttraumatic ventriculomegaly: hydrocephalus or atrophy? A new approach for diagnosis using CSF dynamics. J Neurosurg 1996;85(6):102 6-35.

\section{CrossRef Google Scholar| $\mid$ PubMed}

3. Weintraub AH, Gerber DJ, Kowalski RG. Posttraumatic hydrocephalus as a confounding $i$ nfluence on brain injury rehabilitation: inc $f \mid$ Google Scholar $\mid \underline{\text { PubMed }}$ 
4. Choi I, Park HK, Chang JC, et al. Clinical factors for the development of posttraumatic hy drocephalus after decompressive craniectomy. J Korean Neurosurg Soc 2008;43(5):227-31.

CrossRef| Google Scholar| PubMed

5. Cinalli G, Spennato P, Nastro A, et al. Hydrocephalus in aqueductal stenosis. Child's Ner v Syst 2011;27(10):1621-42.

\section{CrossRef Google Scholar $\mid$ PubMed}

6.De Bonis P, Mangiola A, Pompucci A, et al. CSF dynamics analysis in patients with post-tr aumatic ventriculomegaly. Clin Neurol Neurosurg 2013;115(1):49-53.

CrossRef Google Scholar| $\mid$ PubMed.

7. Dandy WE, Blackfan KD. An experimental, clinical and pathological study. Am J Dis Chil d 1914;8(6):406-82.

Google Scholar| Ding J, Guo Y, Tian H.

8. The influence of decompressive craniectomy on the development of hydrocephalus: a revie w. Arq Neuropsiquiatr 2014;72(9):715-20CrossRef Google Scholar| PubMed

9. Hawkins TD, Lloyd AD, Fletcher GIC, et al. Ventricular size following head injury: a clini co-radiological study. Clin Radiol 1976;27(3):279-89 CrossRef| Google Scholar| PubMed.

10 Classification of hydrocephalus: Critical analysis of classification categories and advanta ges of "multi-categorical Hydrocephalus Classification" (Mc HC). Child's Nerv Syst 2011;2 7(10):1523-33. CrossRef Google Scholar| PubMed.

11. De Bonis P, Anile C. Post-traumatic hydrocephalus: the cinderella of neurotrauma. Expe rt Rev Neurother 2020;20(7):643-6CrossRef| Google Scholar| PubMed

12.Hauk L. Ventriculoperitoneal shunt. AORN J 2018;107(1):P1 .CrossRef| Google

Scholar $\mid$ PubMed.

13. Jiao QF, Liu Z, Li S, et al. Influencing factors for posttraumatic hydrocephalus in patients suffering from severe traumatic brain injuries. Chinese J Traumatol - English Ed. 2007;10(3 ):159-62.Google Scholar.

14. Licata C, Cristofori L, Gambin R, et al. Post-traumatic hydrocephalus. J Neurosurg Sci 2 001;45(3):141-9. Google Scholar.

15.18] Beyer B Black PM. Posttraumatic hydrocephalus. Neurosurgery 1984;15(2):257-61

16. Licata C, Cristofori L, Gambin R, et al. Post-traumatic hydrocephalus. J Neurosurg Sci 2001;45(3):141-9.

17.] Waziri A, Fusco D, Mayer SA, et al. Postoperative hydrocephalus in patients undergoing decompressive hemicraniectomy for ischemic or hemorrhagic stroke. Neurosurgery

2007;61(3):489-93.

18.Tian HL, Хu T, Hu J, et al. Risk factors related to hydrocephalus after traumatic subarach noid hemorrhage. Surg Neurol 2008;69(3):241-6. 